Research Article

\title{
Stability Analysis of Shield Excavation Face Based on Particle Flow in Different Depths of Sandy Gravel Stratum
}

\author{
Zhang Junwei $(\mathbb{D}$, Huang Ling, and Peng Taixin $(\mathbb{D}$ \\ Institute of Geoscience and Technology, Southwest Petroleum University, Chengdu 610500, China \\ Correspondence should be addressed to Peng Taixin; 1834375815@qq.com
}

Received 25 April 2019; Accepted 1 July 2019; Published 23 November 2019

Academic Editor: Abdul Aziz Bin Abdul Samad

Copyright (C) 2019 Zhang Junwei et al. This is an open access article distributed under the Creative Commons Attribution License, which permits unrestricted use, distribution, and reproduction in any medium, provided the original work is properly cited.

\begin{abstract}
The objective of this work was to study the minimum support force of the shield excavation face of sand-gravel stratum. Based on the geological conditions obtained from the exploration of the 18th line of the Chengdu Rail Transit and the shield excavation parameters obtained from excavation, particle flow DEM PFC3D and FLAC3D were used as tools; the digital triaxial compression test was performed to calibrate the mesoscopic parameters of the soil; numerical excavation models were built for deep-buried and shallow-buried sand and gravel stratum shield tunnels; surface settlement and minimum support force under different depths and different supporting forces were obtained in the end. The stability of the excavation face under the condition of $10 \mathrm{kPa} \sim 60 \mathrm{kPa}$ support force was analyzed; the excavation surface gradually tended to stabilize, and the surface subsidence decreased with the increase of support force. When the supporting force was greater than or equal to $3 \mathrm{kPa}$, the excavation surface was stable and the surface settlement speed gradually decreased to zero with time. While analyzing the stability of the excavation face of $5 \mathrm{~m}, 10 \mathrm{~m}$, and $15 \mathrm{~m}$ buried deep gravel tunnels and the influence of the support force on the surface settlement, the minimum support force that did not consider the surface settlement was reduced and the minimum support force required to control the surface settlement was increased as the tunnel depth decreased. Using this method, the depth of the excavation sand-gravel tunnel and the support of the excavation face could be obtained to meet the requirements of surface subsidence control and the economic benefits of the project could be improved.
\end{abstract}

\section{Introduction}

In order to alleviate the traffic pressure in large- and medium-sized cities in China, subway construction has achieved unprecedented development and the shield construction method has been widely used. As with other construction methods, due to geological conditions and construction process limitations, it is difficult to avoid disturbance of the surrounding environment caused by the shield propulsion and even leads to excessive ground subsidence. The damage of this environment mainly depends on the stability of the shield excavation surface, such as the Japanese Yamashitamachi Tunnel, the Beijing Subway Line 10, the Guangzhou Rail Transit Line 4, and the Chengdu Rail Transit Line 1. The instability of the excavation surface causes the ground subsidence and other accidents, so the stability of the excavation surface is an important issue in shield construction.
Since the end of the 19th century, in order to prevent the instability of the tunnel excavation surface as the starting point, the stability analysis of the excavation surface is the core and the minimum support force is determined as the main point. Leca et al. [1-3] theoretically studied the relevant solutions of the ultimate support force of excavation surface. Zhou et al. [4-6] tested the stability and instability failure modes of shield excavation surface. $\mathrm{Bu}$ et al. [7-11] used the numerical simulation method to simulate and restore. The instability of the excavation surface was predicted.

Compared with the experimental and theoretical analyses, the numerical simulation method has the advantages of cost-effectiveness, use in complex geological environment and complex working conditions, simultaneous observation of excavation surface and surface deformation, and easy analysis [11-16]. Therefore, based on the Huojin shield section of Chengdu Metro Line 18, the particle flow discrete 


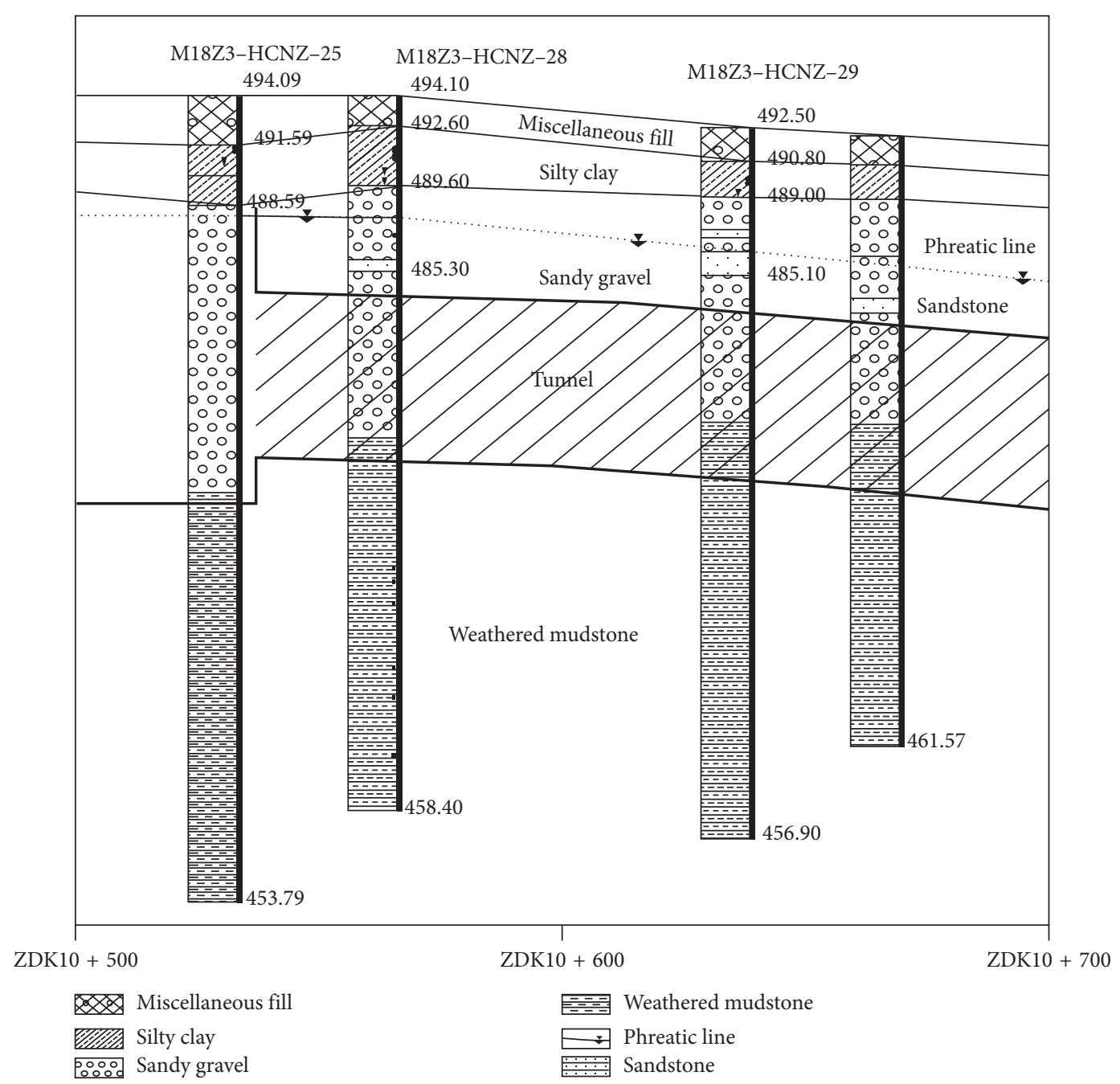

Figure 1: Brief geological profile of tunnel entrance. The profile contains soil type and tunnel excavation situation; M18Z3-HCNZ-25 to 29 represent four drills.

element of the software FLAC3D6.0 is coupled with the finite difference FLAC3D unit, based on the displacement and stress transfer [16-20] and the noncontinuous sand and gravel stratum. The study on the stability of the excavation face reveals the instability mode, surface subsidence law, and minimum support pressure of the collapse and failure of the shield excavation face and compares it with the onsite monitoring data to verify the collapse of the excavation face (research on the universal law of stability influence).

\section{Materials and Methods}

2.1. Project Overview. The geological conditions of the tunnel from the South Railway Station to the Jincheng Square Station of Chengdu Rail Transit Line 18 are shown in Figure 1 . The tunnel is covered with artificial fill, clay, sand pebbles, and $\mathrm{K} 2 \mathrm{~g}$ mudstone. Groundwater is more developed, mainly based on sandy gravel pore water. The tunnel is adjacent to the bus hub of the Chengdu South Railway Station. The tunnel grounds are in Tianfu Avenue. There are a large number of buildings on the left and right sides of the tunnel. There are several tunnels underneath the tunnel section. The tunnels pass through the site, and the underground pipelines are very dense.

Shield tunneling began on May 30, 2017, and ended on November 17, 2017, with an average tunneling speed of approximately $50 \mathrm{~mm} / \mathrm{s}$. On June 5, 2017, the shield tunneled to the tunnel entrance about $15 \mathrm{~m}$, the peak of the daily average of the total thrust peaked $(650 \mathrm{~T})$, and the total thrust on the 7th peaked. As of June 9, 2017, a surface settlement of $-42.59 \mathrm{~mm}$ occurred at approximately $15 \mathrm{~m}$ of the tunnel entrance (Figure 2).

After monitoring the settlement change of the mileage of 10-550, the reinforcement measures such as steel pipe pile protection and concrete pile protection were taken in time, and secondary disasters such as surface settlement were effectively controlled. This paper selects the left line ZDK10 + 550 ZDK10 + 580 section of $30 \mathrm{~m}$ range; the section mainly crosses the sandy gravel stratum; the groundwater level line is about $6.5 \mathrm{~m}$ away from the surface; the buried depth is about $9.5 \mathrm{~m}$; and the measured soil silo pressure is $\sim 23 \mathrm{kPa}$. The main focus is $30 \mathrm{kPa}$, and the 


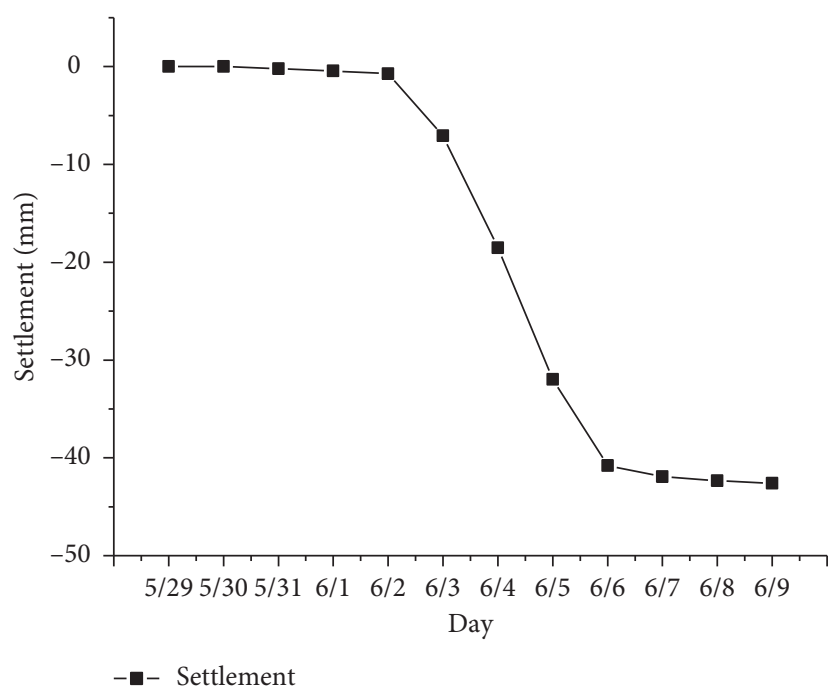

FIgURE 2: Settlement data of DB10550-5 at mile 10-550 monitoring points.

fluctuations are large. The following analysis of the instability and settlement of the excavation face is carried out by numerical simulations to obtain the influence of the support force on the stability of the excavation face.

2.2. Model Parameter Calibration. Particles in PFC were used to simulate different soil layers. The layer of sandy gravel and mudstone is the target layer for tunnel excavation. Through the simulation of a triaxial compression test, the micromechanical parameters $K_{\mathrm{n}}, K_{\mathrm{s}}$, porosity, contact modulus, and friction coefficient of the particles are continuously debugged until the macroscopic physical and mechanical indexes obtained by the simulation. $\gamma, c$, etc. are close to the indoor test results [21-24].

For the numerical triaxial model and the loading process model, refer to Jane et al. [25, 26] By using a triaxial test instrument, unconsolidated undrained numerical triaxial tests were performed in the State Key Laboratory of Chengdu Institute of Technology and Earthquakes $[25,26]$. We compared the stress-strain data of the triaxial compression test results in the natural water-containing state of the medium-density sandy gravel obtained by Jane et al. with the numerical test results obtained by us. The test piece has a height of $600 \mathrm{~mm}$ and a diameter of $300 \mathrm{~mm}$. The soil particles use a ball unit with a diameter of $40 \mathrm{~mm}$. The lateral pressure is provided by the shell unit and the wall-structure unit outside the shell unit. The shell element is $10 \mathrm{~mm}$ thick, and the shell elastic modulus is consistent with the particle contact elastic modulus. Three groups of tests were carried out on the surrounding walls by applying a confining pressure of 100, 200, and $300 \mathrm{kPa}$, and the upper and lower sides were subjected to deviatoric stress and a compression speed of $0.03 \mathrm{~mm} / \mathrm{s}$.

The stress-strain curves obtained in the test have no obvious peaks under different confining pressures, and the strain hardening phenomenon appears to some extent [27]. After the end of the test, the middle portion of the sample bulged (Figure $3(\mathrm{c})$ ). The arrow diagram of the particle displacement (Figure 3(a)) shows the change of the particle displacement field, and the shearing tendency and shear plane of the sample can be seen. The particle contacts the cloud image, the black contact indicates that the parallel bonded portion is not activated, and the white one indicates the parallel bond activation (Figure 3(b)). Most of the soil particles are in good contact. The displacement diagram of the wall shows that the upper and lower compression plates are compressed by $66.022 \mathrm{~mm}$. The housing unit cloud diagram shows the application of a confining pressure of $3 \mathrm{MPa}$.

A numerical triaxial test of mesoscopic parameters of different particles was carried out under confining pressures of $100 \mathrm{kPa}, 200 \mathrm{kPa}$, and $300 \mathrm{kPa}$. Figures $4-9$ show the triaxial stress-strain curves of the mechanical parameters of different particles under the confining pressure of $100 \mathrm{kPa}$. It can be seen that the maximum deviatoric stress of the sandcobble triaxial test positively correlated with the particle friction coefficient, particle contact modulus, and normal stiffness. The maximum deviatoric stress negatively correlated with porosity. According to the stress-strain curves of different particle radii in Figure 10, it is found that the particle radius has little effect on the mechanical properties of sandy gravel and provides experimental support for adjusting the particle radius in the model.

After the above calibration of the six particle mesoscopic parameters, the triaxial test results (Figure 10) which are close to the normal test results are obtained; that is, the calibration is completed.

The triaxial simulation test combined with the indoor triaxial test (Figure 10) calibrated the mesoscopic parameters of the sandy gravel (Table 1), which laid the foundation for the numerical simulation of the tunnel surface stability analysis.

2.3. Calculation Model. Due to the nonexcavation target layer of the silty clay and the mixed filling layer, the influence of the tunnel excavation is mainly due to the load; the composite 


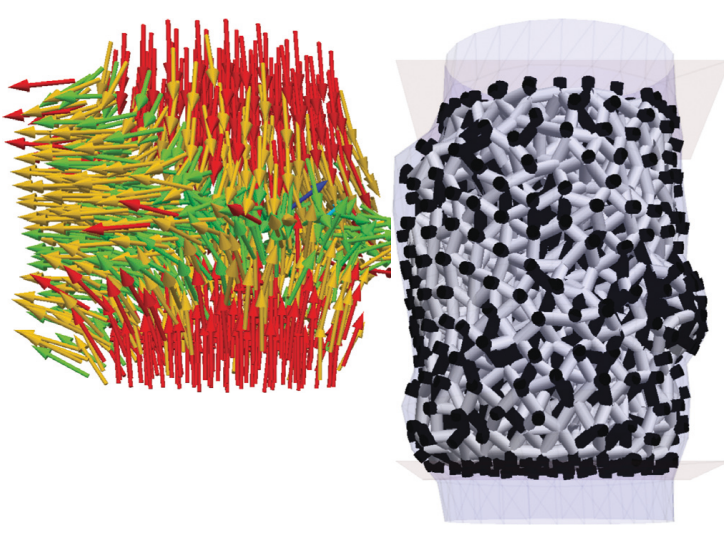

(a)

(b)

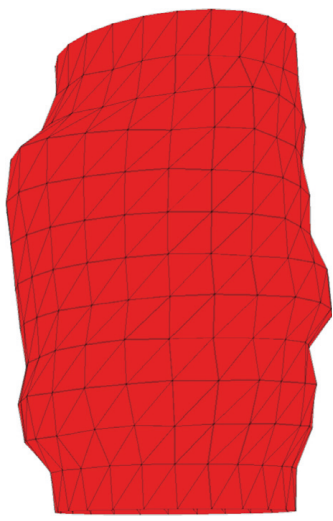

(c)

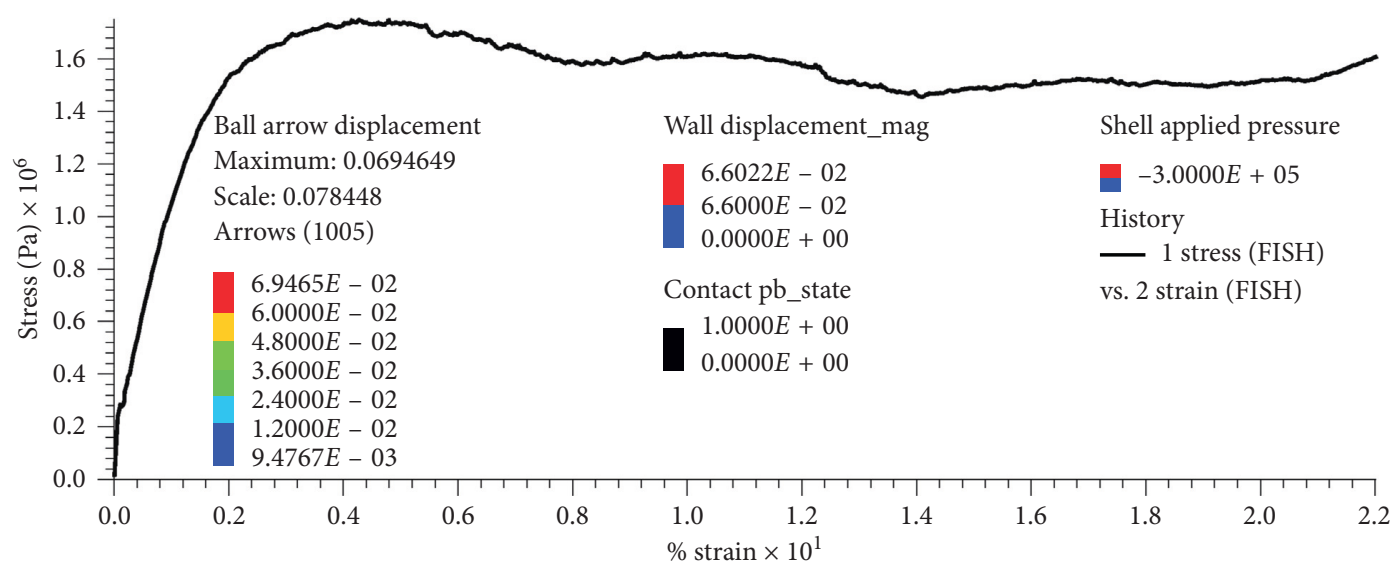

(d)

Figure 3: The three-axis numerical test of flexible servosystem under confining pressure of $300 \mathrm{kPa}$ sandy gravel.

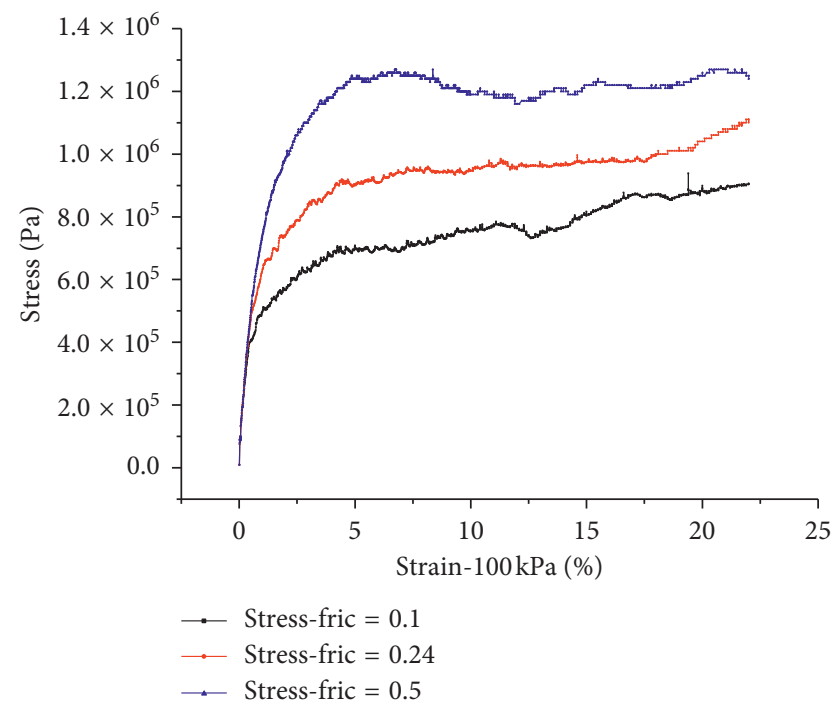

FIGURE 4: Stress-strain of different frictions under $100 \mathrm{kPa}$.

stratum formed by the combination of the underlying mudstone is not considered for the time being. Simplify the model and replace the miscellaneous fill, silty clay, and middle

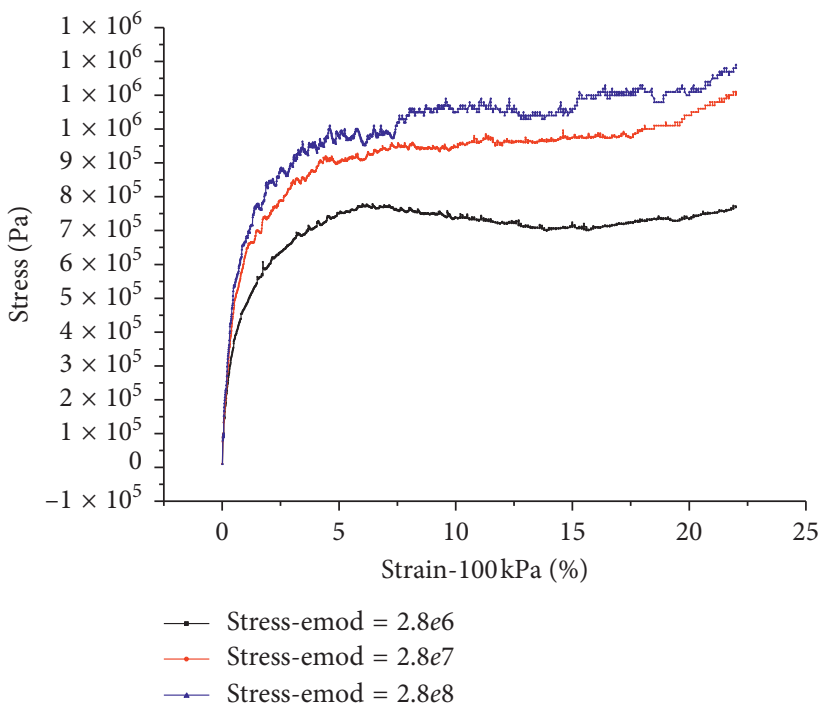

FIGURE 5: Stress-strain of different contact moduli.

weathered mudstone layers with different-density sand and gravel layers to achieve the purpose of highlighting the research. 


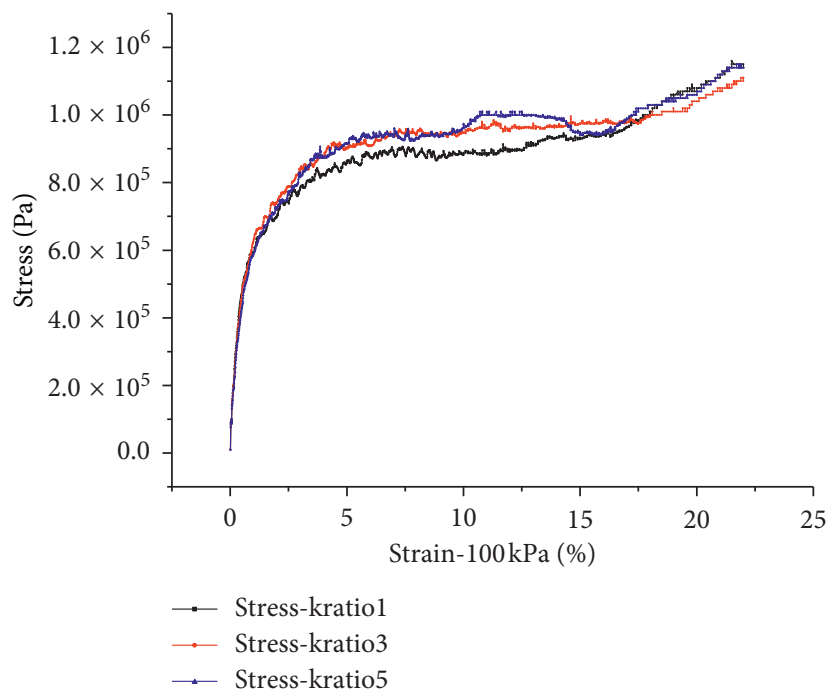

Figure 6: Stress-strain of different stiffness ratios.

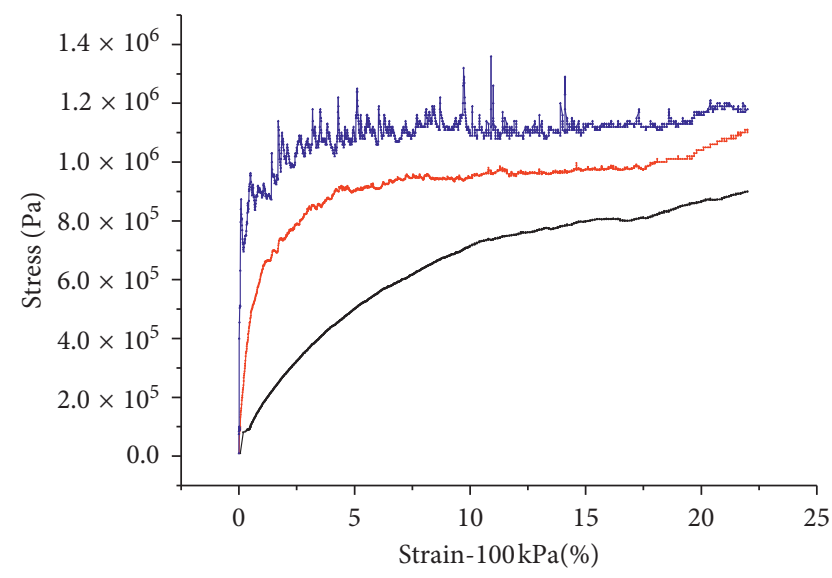

$\longrightarrow$ Stress-kn3.5e5
$\longrightarrow$ Stress-kn3.5e6
$\longrightarrow$ Stress-kn3.5e7

Figure 7: Stress-strain of different normal stiffness values.

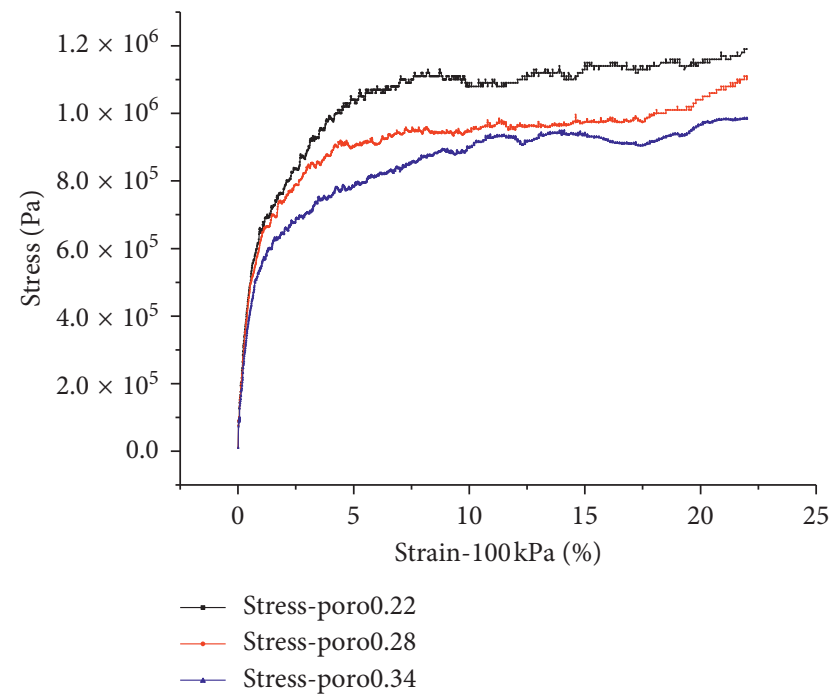

FIGURE 8: Stress-strain of different particle porosities.

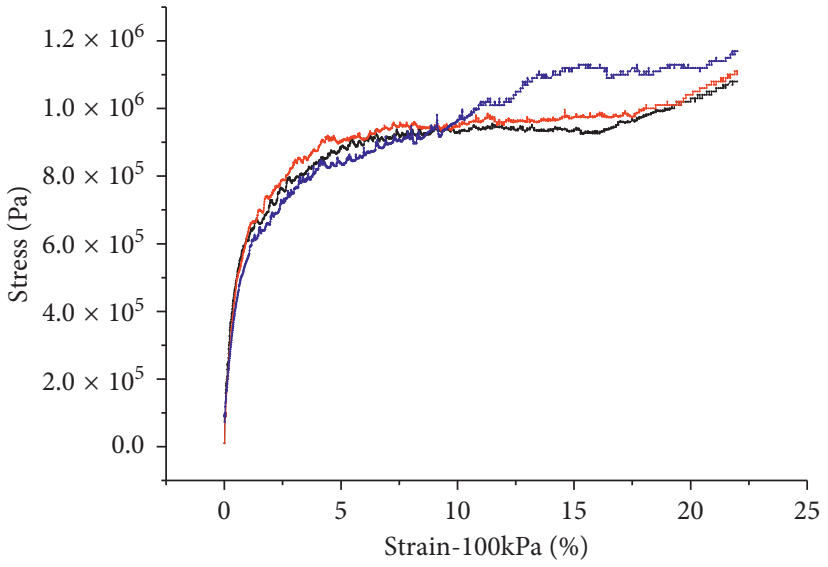

$\longrightarrow$ Stress-radius 0.015

$\longrightarrow$ Stress-radius 0.02

—. Stress-radius 0.025

Figure 9: Stress-strain of different particle radii.

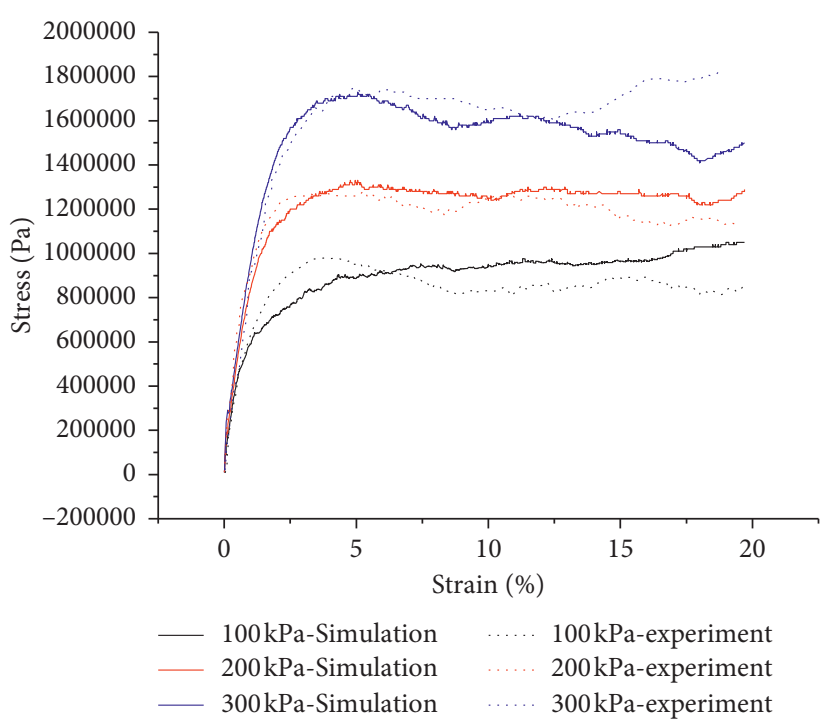

Figure 10: Comparison of triaxial test data [12] and simulation results for sandy gravels. 
TABLE 1: Testing mesoscopic parameters.

\begin{tabular}{lcccccc}
\hline Poisson ratio (test) & Cohesion (test) & $\begin{array}{c}\text { Internal friction } \\
\text { angle (test) }\end{array}$ & Equivalent modulus Coefficient of friction & $\begin{array}{c}\text { Porosity } \\
\text { Stiffness } \\
\text { ratio }\end{array}$ & $\begin{array}{c}\text { Normal contact } \\
\text { stiffness }\end{array}$ \\
\hline Parameters (unit) & $c(\mathrm{kPa})$ & $\Phi\left(^{\circ}\right)$ & $E_{\mathrm{c}}(\mathrm{Pa})$ & $c$ & $K_{\mathrm{n}} * K_{\mathrm{s}}^{-1}$ & $K_{\mathrm{n}}(\mathrm{Pa})$ \\
0.3 & 143.9 & 35.9 & $2.85 e 7$ & 0.24 & 0.28 & 3 \\
\hline
\end{tabular}

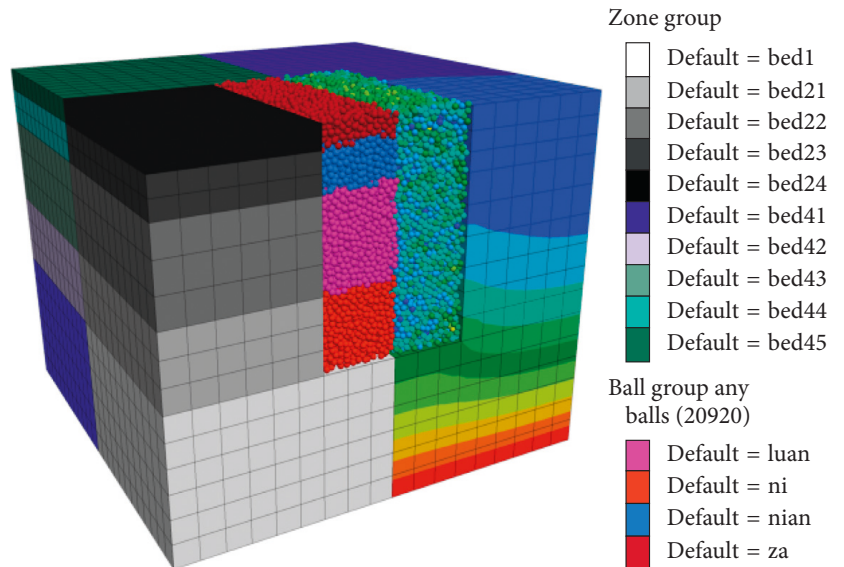

Figure 11: Model grouping and postequilibrium displacement change gram.

Based on the mileage of $10-537$ to $10-600$, a tunnel model of sandy gravel formation was established. The model length is $60 \mathrm{~m}$, the width is 6 times $48 \mathrm{~m}$ of the tunnel diameter, the model height is $47 \mathrm{~m}$, the overlying soil layer is $15 \mathrm{~m}$, the inner diameter of the tunnel is $7.5 \mathrm{~m}$, and the outer diameter is $8.3 \mathrm{~m}$. The soil to be excavated and the area to be laid are preset, and the excavation depth is preset, $15 \mathrm{~m}$. When the overall model size is more than 30 times the average particle size of the particles, the size effect can be neglected [28] and combined with aesthetics and computer operating speed; the particle size is $400 \mathrm{~mm}$ (Figure 11).

Due to the main research on the stability of the excavation surface, the soil arching effect, and the surface subsidence caused by the instability of the excavation surface, the geotechnical parameters obtained from the geological survey and the triaxial tests are used to obtain the geotechnical parameters combined with the previous excavation parameters and monitoring data. Different supporting forces cause different stability of the excavation face and surface settlement.

2.4. Simulation Method. "The design idea of this simulation scheme is divided into two parts. One is to directly apply $30 \mathrm{kPa}$ support pressure to the excavation face after excavation to simulate the silo pressure (Figure 12(a)); the other is to fix the lining and the displacement of the excavation face waiting for the soil. After balancing, the resurfacing face retaining force is $30 \mathrm{kPa}$ (Figure $12(\mathrm{~b})$ ). After the excavation surface is basically stable, the upper arch position in Figure 12(a) mainly appears below the lining (deleting the void position where the particles appear), and the upper arch

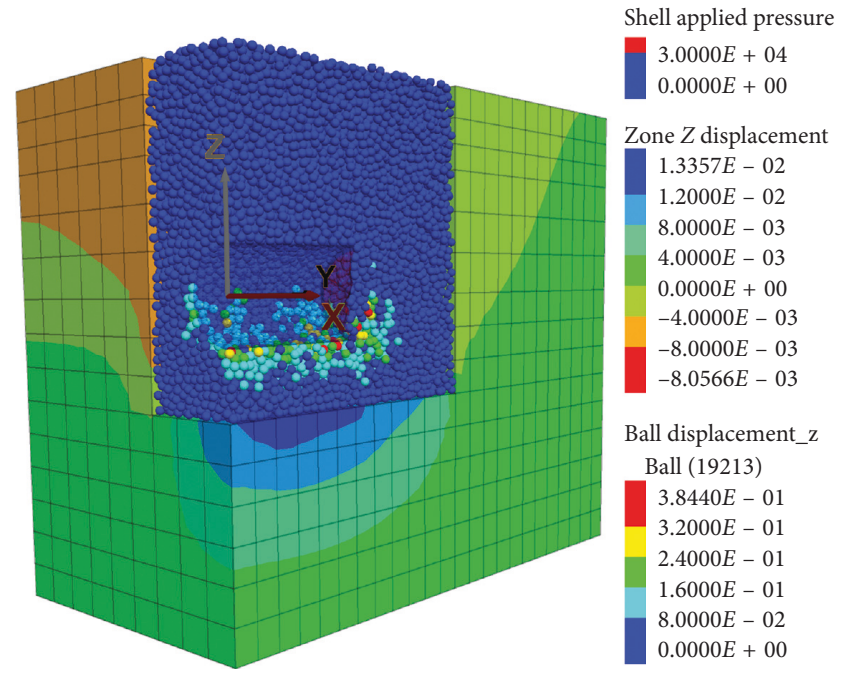

(a)

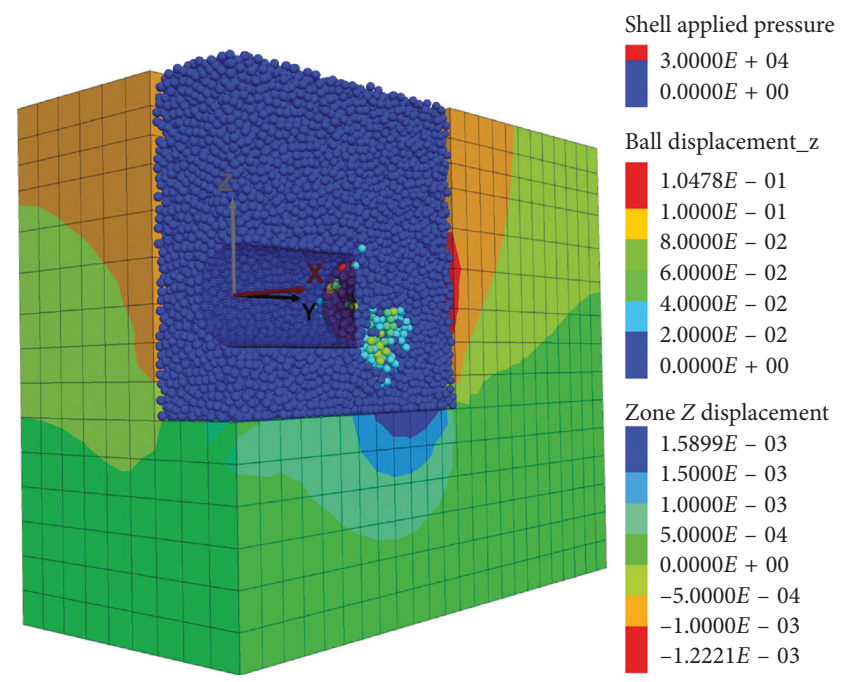

(b)

FIgURE 12: Excavation surface displacement cloud under support force of $30 \mathrm{kPa}$. (a) Excavation-support. (b) Excavation-fix-support.

position of the soil in Figure 12(b) appears in front of the excavation surface, which is more consistent with the actual situation. Therefore, the excavation-fixation-support simulation scheme was chosen.

A monitoring point is arranged in the soil perpendicular to the excavation face and $0.5 \mathrm{~m}$ away from the center of the excavation face. The point is vertically upward to the ground and 3 monitoring points are continuously laid (Figure 13). 


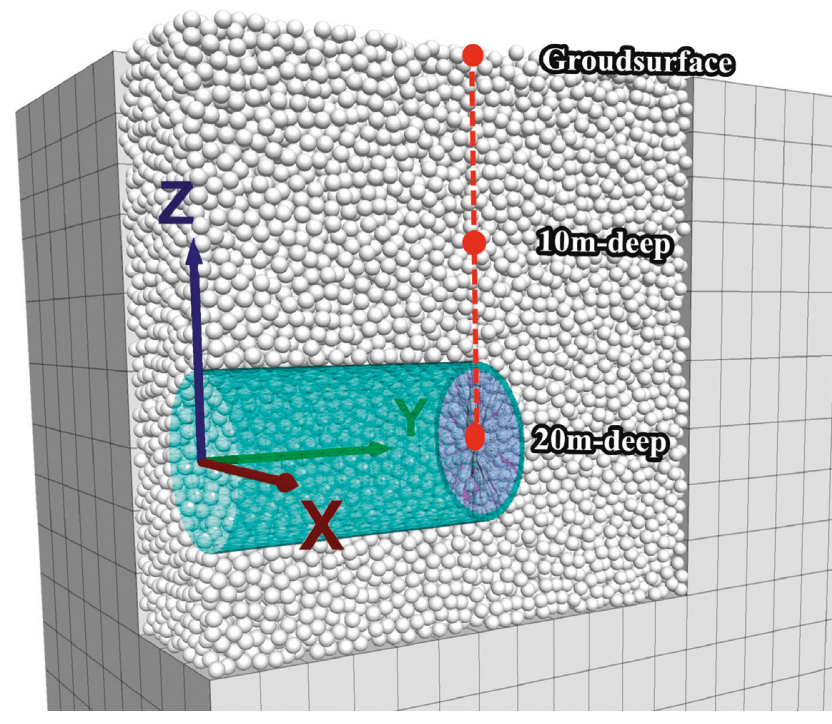

FIGURE 13: Layout of monitoring points.

\section{Simulation Calculation Results and Analysis}

3.1. Soil Instability Mode in front of Shield Excavation. Figure 14 shows the deformation of the excavation face over time without support. It can be seen from the figure that for any location of the excavation face, the initial instability of the tunnel occurs in the soil in front of the excavation face. With the increase of the number of running steps, the soil decreases rapidly, the displacement increases, the instability zone expands, and gradually develops into a chimney shape; as the number of running steps increases further, the instability continues to develop into a wedge shape and finally the instability The area penetrates to the surface to form a large range of subsidence and even collapse.

3.2. Excavation Surface and Surface Soil Displacement Response under Different Supporting Forces. After the excavation-fixation phase is equilibrated, in order to observe the continuous deformation of the excavation face, a casing unit is provided on the excavation face and the unit modulus is set to $1 e 5 \mathrm{~Pa}$. As shown in Figure 15, when the modulus is too small $(1 e 4 \mathrm{~Pa})$, the housing unit is deformed greatly and discontinuously. When the modulus is too large (1e6 Pa), the deformation of the housing unit is small, which is inconvenient to observe.

The dichotomy to take the support force and position the support force that can balance the excavation face to the $20-40 \mathrm{kPa}$ range is used. A support force of $20 \mathrm{kPa}, 30 \mathrm{kPa}$, and $40 \mathrm{kPa}$ was applied to the excavation face to observe the development of the surface deformation with time (Figure 16). As shown in Figure 16, as the support force, shell applied pressure, increases, the displacement of the excavation face and surrounding soil decreases.

As shown in the surface subsidence monitoring curve of Figure 17, under the action of $20 \mathrm{kPa}$ excavation surface support, the soil displacement curve does not converge, that is, the excavation surface is unstable; under the action

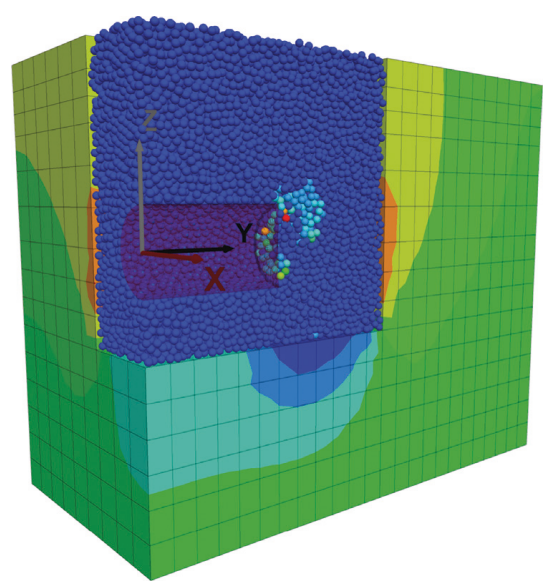

(a)

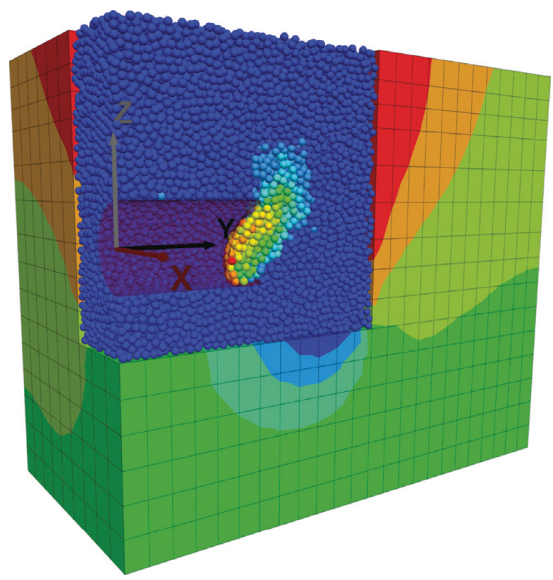

(b)

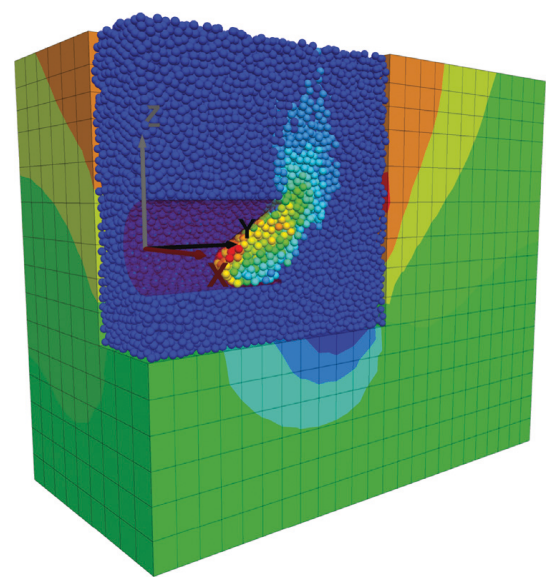

(c)

FIGURE 14: Deformation of excavation surface increasing with time without support.

of $30 \mathrm{kPa}$ and $40 \mathrm{kPa}$ support forces, the surface settlement curve converges and the maximum settlement decreases as the support force increases. The following specific analysis of the displacement of sandy gravel is under $30 \mathrm{kPa}$ support force.

As shown in Figure 18, under the support of $30 \mathrm{kPa}$, the soil in front of the excavation face is first swelled for about 


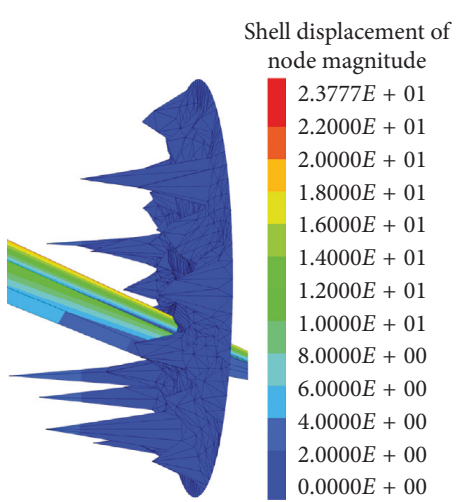

(a)

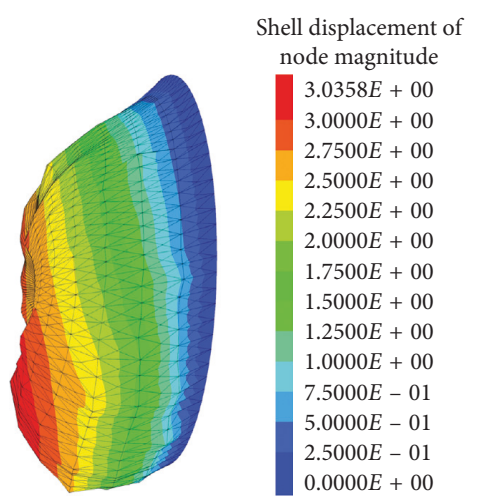

(b)

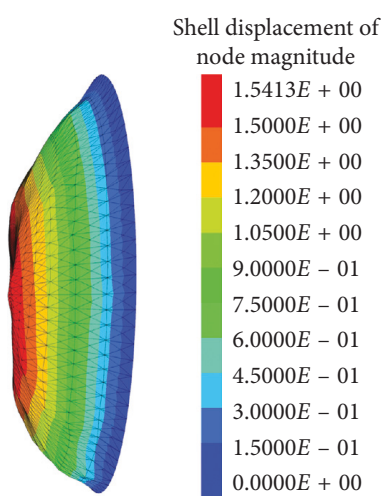

(c)

Figure 15: No support elastic modulus of shell (1e4, 1e5, and 1e6).

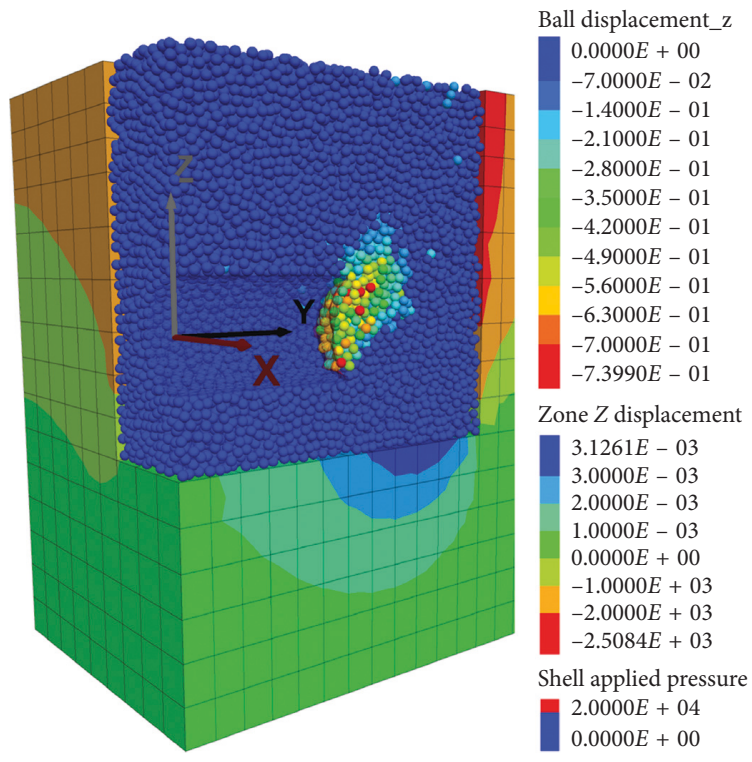

(a)

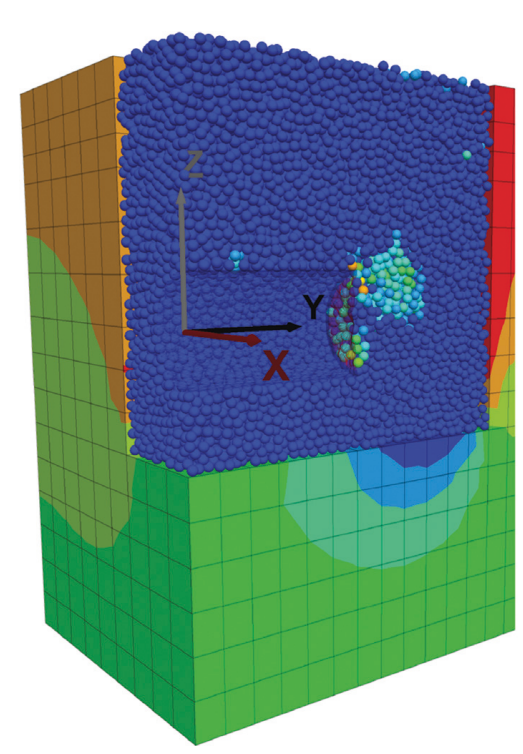

(b)

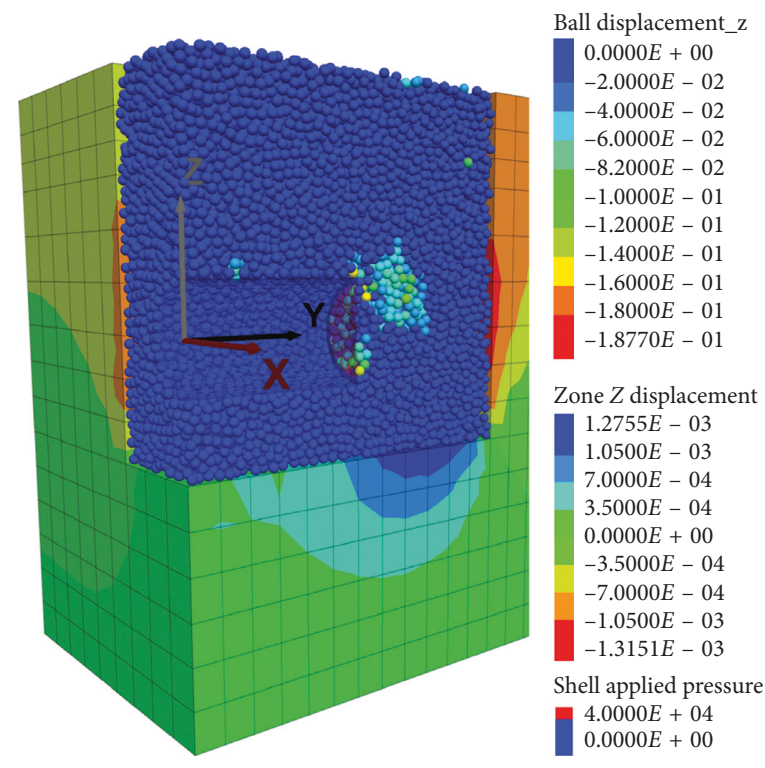

(c)

Figure 16: Soil deformation of $20 \mathrm{kPa}, 30 \mathrm{kPa}$, and $40 \mathrm{kPa}$ supporting forces. 


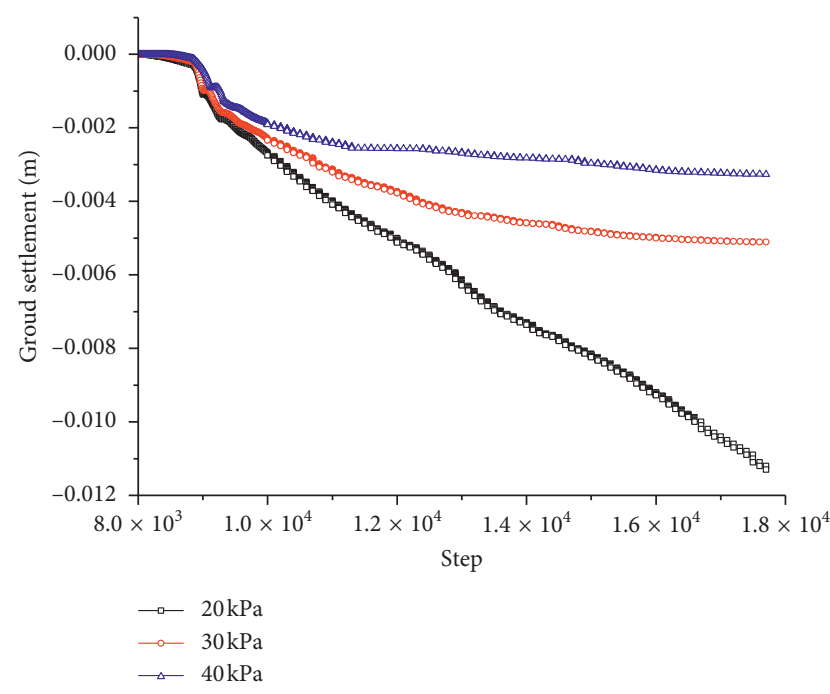

FIgURE 17: Surface subsidence under different support forces.

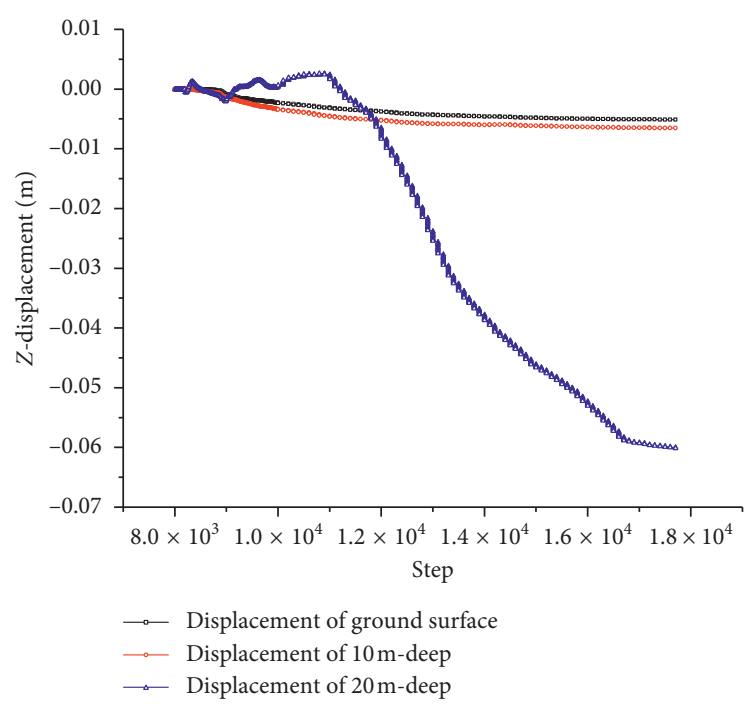

Figure 18: Upper and lower parts of soil.

$4 \mathrm{~mm}$ and then settled to about $60 \mathrm{~mm}$, which tends to be stable. The soil in front of the excavation face and the surface soil are at the settlement speed. Time is gradually decreasing.

As shown in Figure 19, the maximum settlement of the surface is about $5 \mathrm{~mm}$, which meets the engineering safety requirements and has little impact on the surrounding structures. Therefore, $30 \mathrm{kPa}$ is the proper support force of a " $15 \mathrm{~m}$ buried depth, $15 \mathrm{~m}$ footage, and $8 \mathrm{~m}$ diameter" tunnel.

3.3. Stability Analysis of Shield Excavation Face at Different Depths. As shown in Figure 20, under different buried depths, the excavation surface is unstable and maintains a similar failure shape and finally presents a wedge-shaped instability failure zone. As the depth of the burial decreases, the extent of the instability zone decreases and penetrates the surface and the surface settlement becomes larger (Figure 21). Due to the soil arching effect, when the buried depth is large, the soil damage does not penetrate the surface, which indicates that there is a certain range of instability and damage, and the excavation surface will not be completely unstable.

When the buried depth is different, different support forces are applied to the excavation face to observe the instability of the excavation face, and the data such as surface displacement and displacement in the soil are monitored. From the stability analysis of the excavation face under different support forces in the previous section, it can be seen that under other conditions, the surface settlement decreases with the increase of the support force of the excavation face. The support force that converges the surface settlement curve (the surface settlement rate is 0 ) is referred to herein as the ideal minimum support force. As shown in Figures 22 and 23 , as the buried depth becomes shallower, the ideal minimum support force becomes smaller, but the surface settlement becomes larger.

The control of surface settlement is the key to ensure the safety of shield construction. Generally, the settlement of $5 \mathrm{~mm}$ is used as the control standard. Under the requirement of settlement control, the support force of $1 e 4-8 e 4$ is applied to the tunnel excavation faces of different depths to obtain the minimum support force. It can be obtained from the above curve (Figure 24) that the $5 \mathrm{~m}$ buried tunnel is under $40 \mathrm{kPa}$ supporting force. The maximum settlement of the surface exceeds $5 \mathrm{~mm}$, which does not meet the engineering safety requirements. Under the support force of $50 \mathrm{kPa}$, the maximum settlement of the ground surface is about $3.1 \mathrm{~mm}$, which meets the safety requirements.

It can be obtained from the above curve (Figure 25) that the $5 \mathrm{~m}$ buried tunnel is under $30 \mathrm{kPa}$ supporting force. The maximum settlement of the surface exceeds $5 \mathrm{~mm}$, which does not meet the engineering safety requirements. Under the $40 \mathrm{kPa}$ support force, the maximum settlement of the ground surface is about $4.2 \mathrm{~mm}$, which meets the safety requirements.

The minimum support force at different depths is obtained by fitting the above three different support force curves (Figures 17 and 24-26), which can be obtained from Figures 23 and 26, as the tunnel depth becomes deeper. The minimum support force that does not control the surface settlement is becoming larger, and the minimum support force required to control the surface settlement is also becoming larger.

After analysis, the support force of the sandy gravel tunnel increases with the increase of depth, which is consistent with the "silos theory". After the deep embedding of the gravel tunnel and the displacement of the excavation surface, the soil arching effect appears on the soil above the excavation surface to form a soil arch, which makes the surface settlement less. A shallow gravel tunnel with a shallow depth can be used to stabilize the excavation surface with a small excavation surface support, but it will produce a large surface settlement. If the settlement of the shallow- 


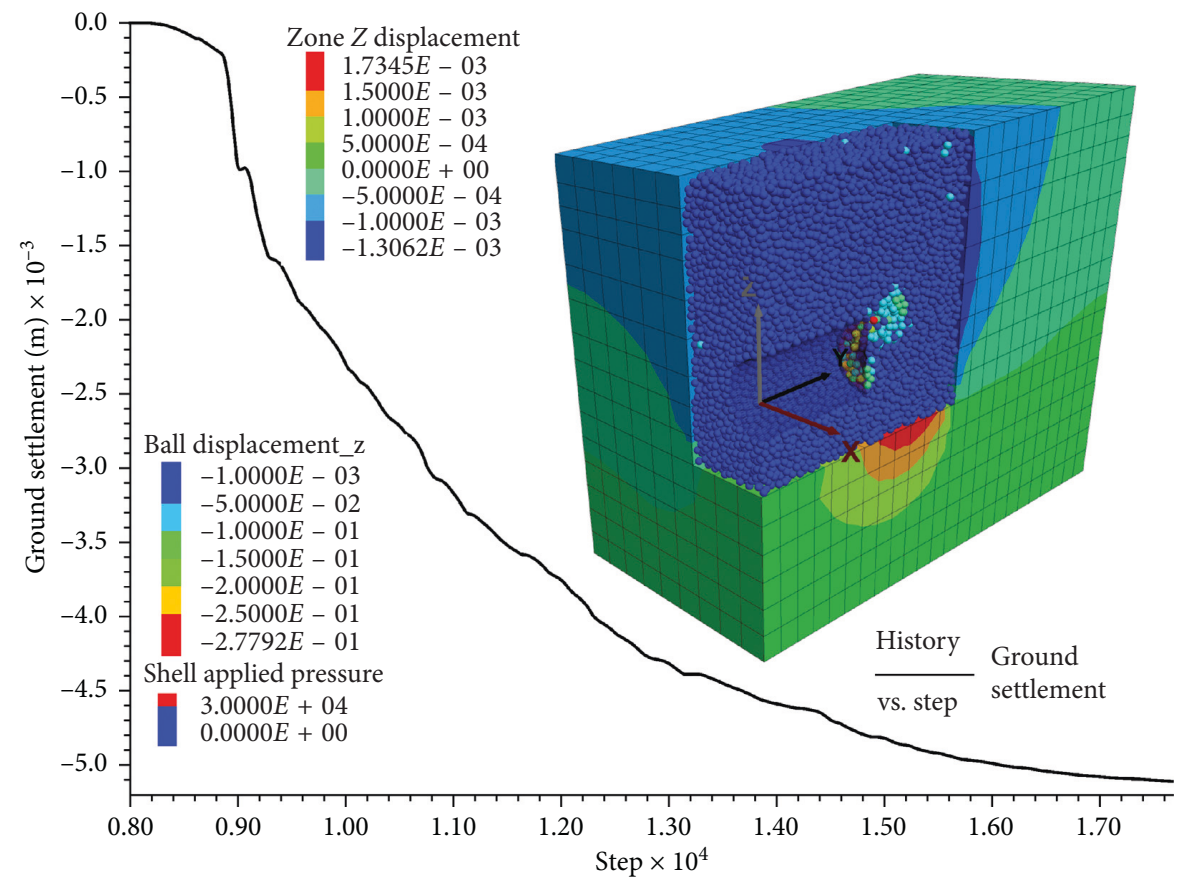

Figure 19: Displacement response of soil and surface settlement curve under supporting force of $30 \mathrm{kPa}$.

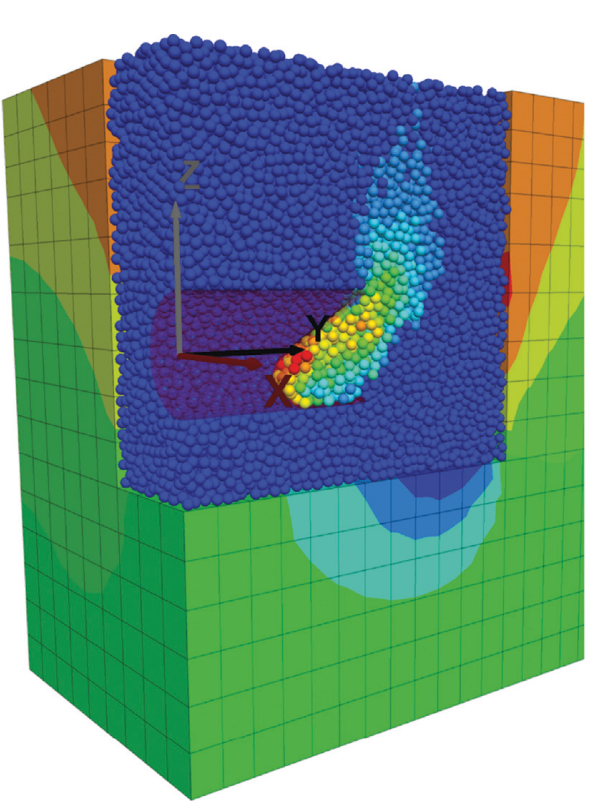

(a)
Zone $Z$ displacement

$7.4669 E-03$
$6.0000 E-03$
$4.0000 E-03$
$2.0000 E-03$
$0.0000 E+00$
$-2.0000 E-03$
$-4.0000 E-03$
$-6.0000 E-03$
$-6.3815 E-03$

Ball displacement_z

$0.0000 E+00$

$-5.0000 E-01$

$-1.0000 E+00$

$-1.5000 E+00$

$-2.0000 E+00$

$-2.5000 E+00$

$-3.0000 E+00$

$-3.5000 E+00$

$-4.0000 E+00$

$-4.5000 E+00$

$-5.0000 E+00$

$-5.5000 E+00$

$-5.7778 E+00$

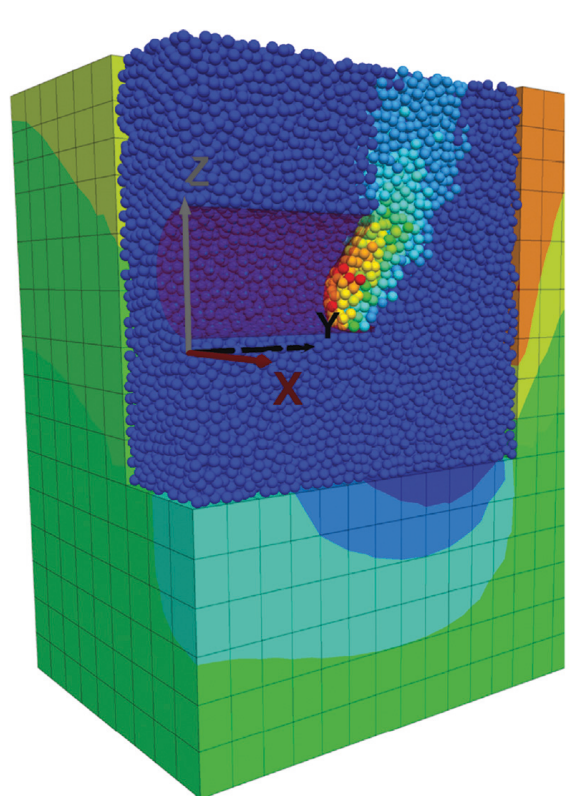

(b)
Zone $Z$ displacement

$3.0793 E-03$

$3.0000 E-03$

$2.0000 E-03$

$1.0000 E-03$

$0.0000 E+00$

$-1.0000 E-03$

$-2.0000 E-03$

$-3.0000 E-03$

$-3.1361 E-03$

Ball displacement_z

$0.0000 E+00$

$-3.0000 E-01$

$-6.0000 E-00$

$-9.0000 E-00$

$-1.2000 E+00$

$-1.5000 E+00$

$-1.8000 E+00$

$-2.1000 E+00$

$-2.4000 E+00$

$-2.7000 E+00$

$-3.0000 E+00$

$-3.2734 E+00$

Figure 20: Continued. 


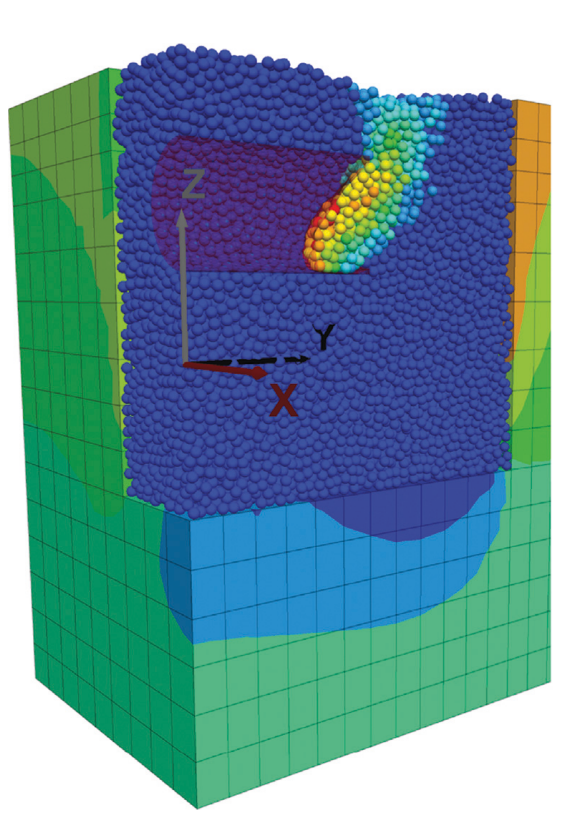

(c)
Zone $Z$ displacement

$1.2532 E-03$

$1.0000 E-03$

$5.0000 E-04$

$0.0000 E+00$

$-5.0000 E-04$

$-1.0000 E-03$

$-1.5000 E-03$

$-1.5171 E-03$

Ball displacement_Z

$0.0000 E+00$

$-5.0000 E-01$

$-1.0000 E+00$

$-1.5000 E+00$

$-2.0000 E+00$

$-2.5000 E+00$

$-3.0000 E+00$

$-3.5000 E+00$

$-4.0000 E+00$

$-4.5000 E+00$

$-5.0000 E+00$

$-5.2424 E+00$

$-5.2424 E+$

FIGURE 20: Instability of excavation surface at different depths.

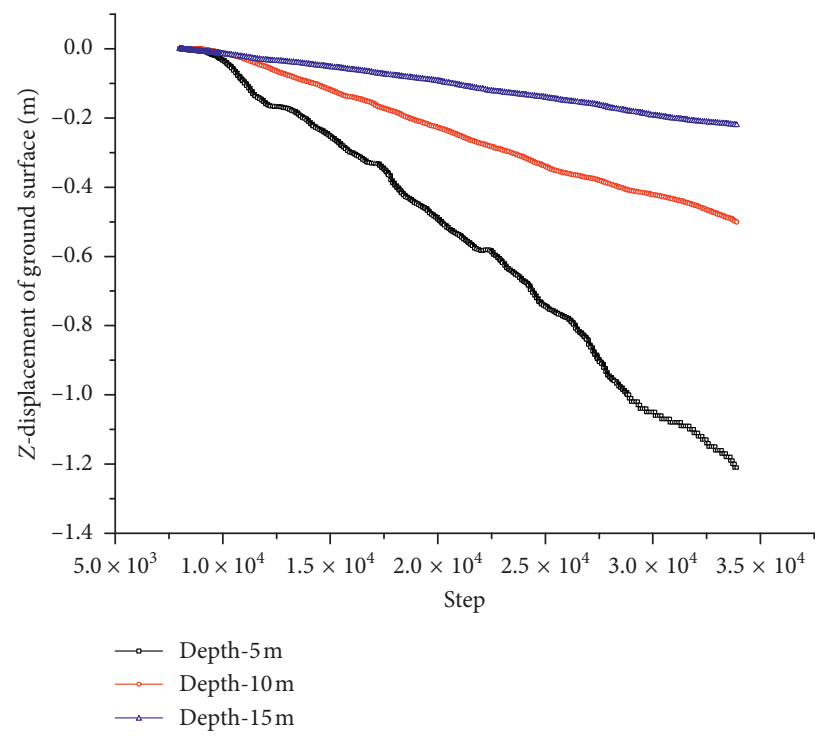

Figure 21: The subsidence curve of surface soil under different depths.

buried gravel tunnel is to be controlled, the applied excavation face support force will be larger than the deeply buried sandy gravel tunnel under the same conditions. In the sandy gravel stratum area where the ground subsidence value is large, the shallow-buried tunnel is selected for excavation with lower support force, which can save cost and improve efficiency. In the sand-gravel stratum area where the ground settlement control is strict, the tunnel with a buried depth of $15 \mathrm{~m}$ or more can be used to obtain a relatively low minimum support force, which can also improve economic benefits.

\section{Results and Discussion}

(1) The numerical triaxial compression test calibrates the mesoscopic parameters of the Chengdu sandy gravel stratum, and the sandy gravel exhibits the property of strain hardening.

(2) The excavation analysis of the shield by excavationfixation-support is simulated, and the shell with the elastic modulus of $1 e 5$ is supported. The deformation of the excavation face support shell is continuous, and the soil deformation is easy to observe. The formation 


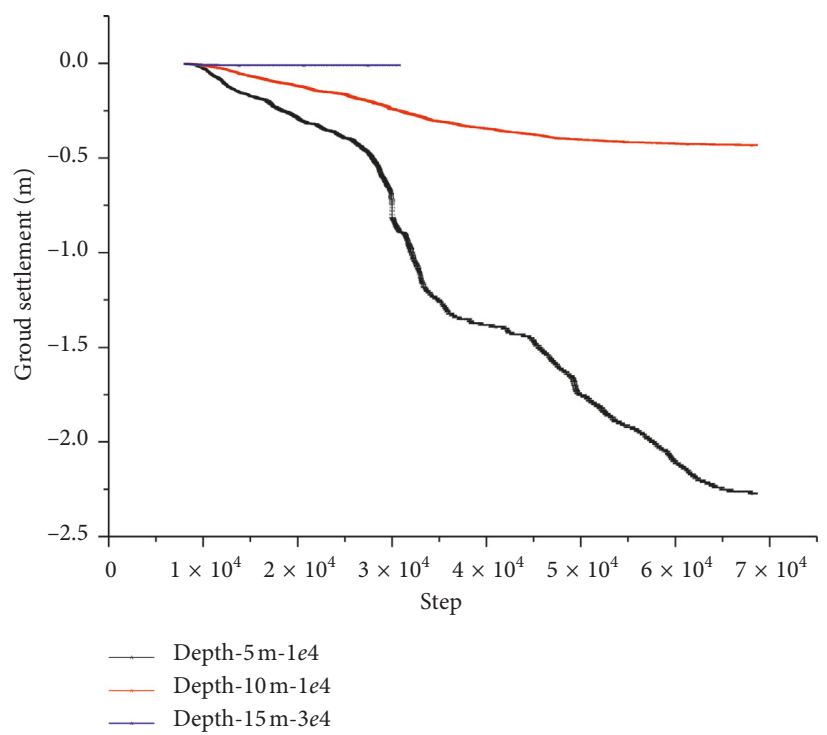

FIGURE 22: Convergence curves of surface subsidence.

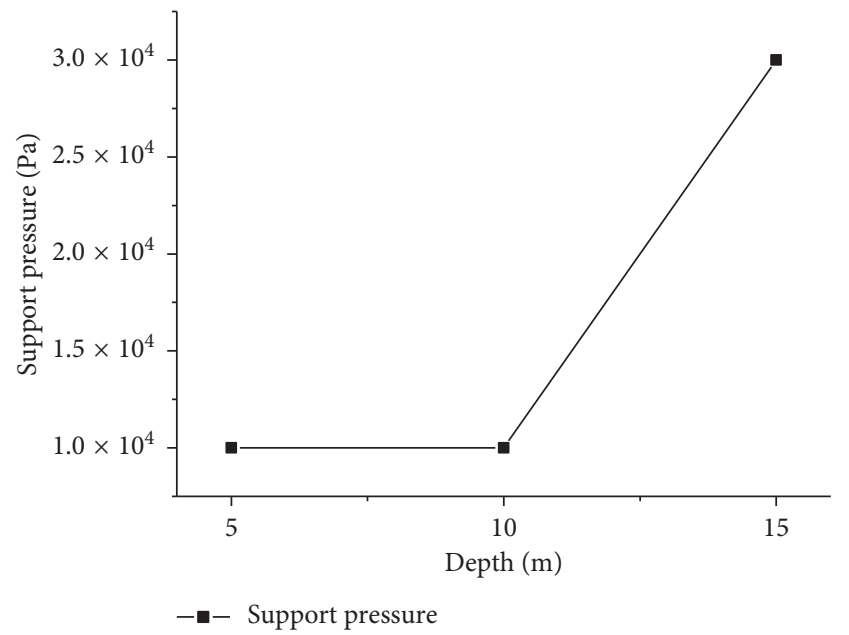

Figure 23: Ideal minimum support force.

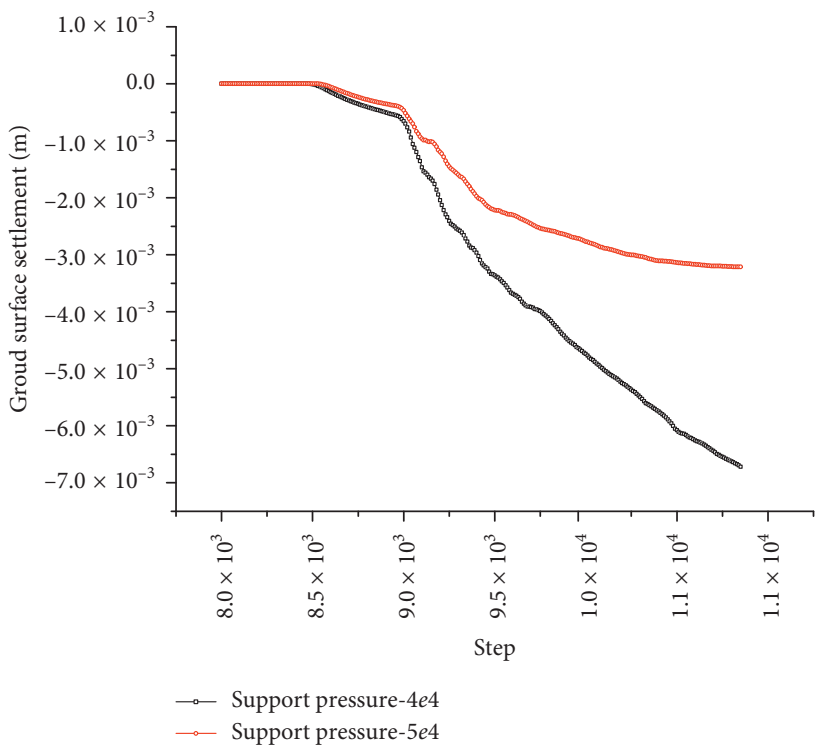

Figure 24: Displacement curve of $5 \mathrm{~m}$ buried depth under different supporting forces.

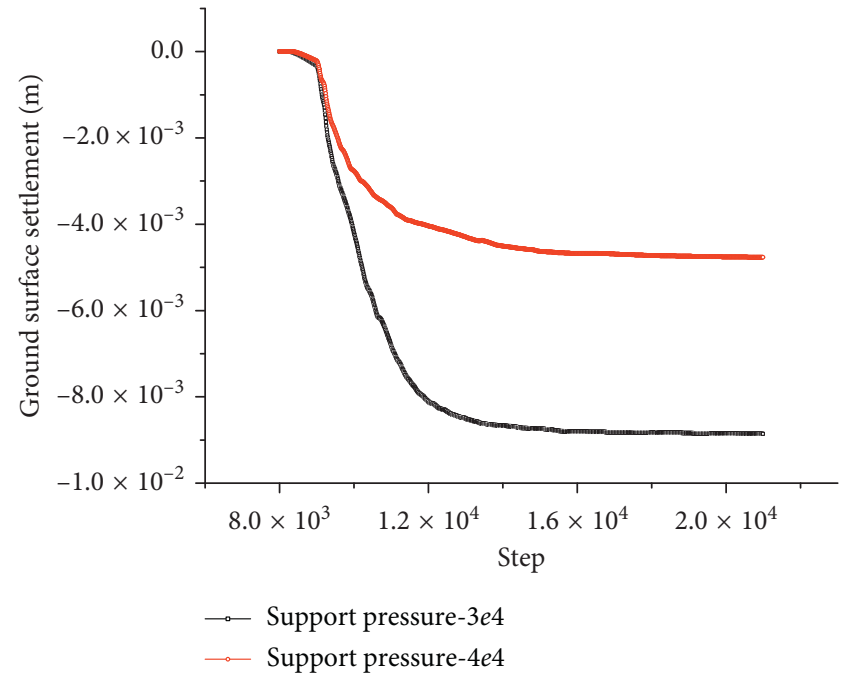

Figure 25: Displacement curve of $10 \mathrm{~m}$ buried depth under different supporting forces.

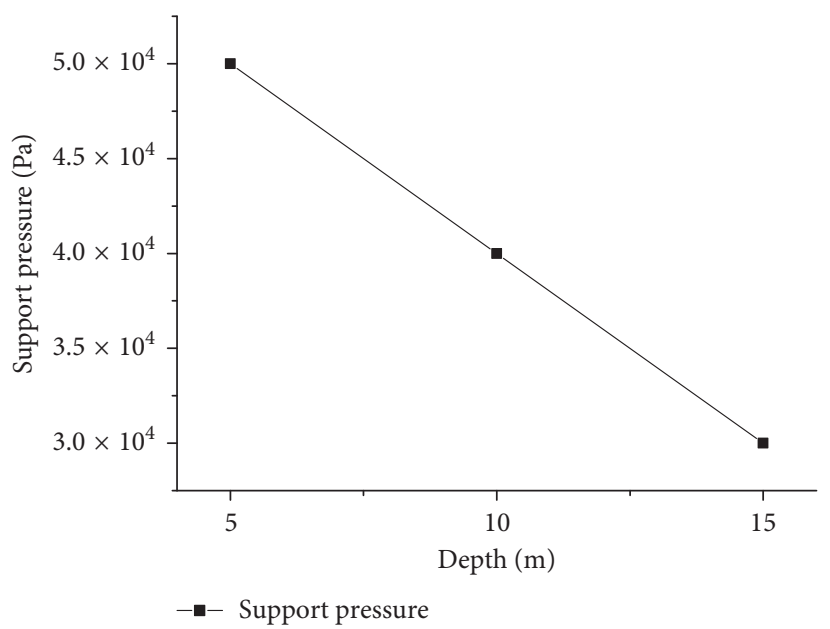

FIgURE 26: Minimum support force at different depths in controlling surface settlement. 
process of the "chimney-like" wedge body of the excavation face under unsupported force is obtained.

(3) Based on the numerical model established by the engineering example, the stability of the excavation face under the condition of $10 \mathrm{kPa}-60 \mathrm{kPa}$ support force is analyzed, and the surface settlement decreases with the increase of the support force.

(4) The stability of the excavation face of the $5 \mathrm{~m}, 10 \mathrm{~m}$, and $15 \mathrm{~m}$ buried deep gravel tunnels and the influence of the support force on the surface settlement is analyzed. It is obtained that as the tunnel depth decreases, the minimum support force that does not consider the surface settlement is reduced and the minimum support force that needs to control the surface settlement is increased. The above method can be used, combined with the requirements of surface subsidence control, to select the safe and economical sandy gravel tunnel buried depth and support force.

\section{Data Availability}

The data used to support the findings of this study are available from the corresponding author upon request.

\section{Conflicts of Interest}

The authors declare that there are no conflicts of interest regarding the publication of this paper.

\section{Acknowledgments}

This work was supported by the Sichuan Science and Technology Project (No. 2019YJ0349).

\section{References}

[1] E. Leca and L. Dormieux, "Upper and lower bound solutions for the face stability of shallow circular tunnels in frictional material," Géotechnique, vol. 40, no. 4, pp. 581-606, 1990.

[2] A. H. Soubra, "Three-dimensional face stability analysis of shallow circular tunnels," in Proceedings of the ISRM International Symposium, Melbourne, Australia, November 2000.

[3] W. Broere, Tunnel Face Stability and New CPT Applications, Delft University Press, Delft, Netherlands, 2001.

[4] X. W. Zhou, J. Q. Zhi, and S. Bao, "Centrifugal model test of displacement and failure of crown soil in tunnel," Geotechnical Mechanics, vol. 20, no. 2, pp. 32-36, 1999.

[5] G. Idinger, P. Aklik, W. Wu, and R. I. Borja, "Centrifuge model test on the face stability of shallow tunnel," Acta Geotechnica, vol. 6, no. 2, pp. 105-117, 2011.

[6] H. H. Zhu, Q. W. Xu, S. M. Liao et al., "Model test of jacking thrust in EPB shield construction," Geotechnical Mechanics, vol. 28, no. 8, pp. 1587-1594, 2007.

[7] H. P. Bu, A. Cuvillier, and L. Dormieux, "“Face stability of shallow circular tunnels driven under the water table," a numerical analysis," International Journal for Numerical and Analytical Methods in Geomechanics, vol. 23, no. 3, pp. 79-95, 1999.
[8] Y. Li, F. Emeriault, R. Kastner, and Z. X. Zhang, "Stability analysis of large slurry shield-driven tunnel in soft clay," Tunneling and Underground Space Technology, vol. 18, no. 2, pp. 205-212, 2009.

[9] R. P. Chen, L. J. Tang, D. S. Ling, and Y. M. Chen, "Face stability analysis of shallow shield tunnels in dry sandy ground using the discrete element method," Computers and Geotechnics, vol. 38, no. 2, pp. 187-195, 2011.

[10] Y. X. Bai, Influencing Factors and Control Measures of Deep Foundation Pit Deformation in Soft Soil Subway Station, Southwest Jiaotong University, Chengdu, China, 2006.

[11] Y. X. Bai, Study on Mechanism and Countermeasures of Stratum Collapse Induced by Shield Tunneling in Water-Rich Sandy Pebble Stratum, Southwest Jiaotong University, Chengdu, China, 2012.

[12] D. Debasis and K. C. Das, "Bolt-grout interactions in elastoplastic rock mass using coupled FEM-FDM techniques," Advances in Civil Engineering, vol. 8, no. 13, 2010.

[13] J. Hadjigeorgiou, K. Esmaieli, and M. Grenon, "Stability analysis of vertical excavations in hard rock by integrating a fracture system into a PFC model," Tunnelling and Underground Space Technology, vol. 24, no. 3, pp. 296-308, 2009.

[14] J. Mingjing and Z. Y. Yin, "Analysis of stress redistribution in soil and earth pressure on tunnel lining using the discrete element method," Tunnelling and Underground Space Technology, vol. 32, no. 6, pp. 251-259, 2012.

[15] Y. Sun, F. Xianda, and Y. Lingqiang, "Predicting tunnel squeezing using multiclass support vector machines," $A d$ vances in Civil Engineering, vol. 1, no. 12, 2018.

[16] L. Wu, T. Guan, and L. Lei, "Discrete element model for performance analysis of cutterhead excavation system of EPB machine," Tunnelling and Underground Space Technology, vol. 37, no. 6, pp. 37-44, 2013.

[17] X. Yang, P. H. S. W. Kulatilake, H. Jing, and S. Yang, "Numerical simulation of a jointed rock block mechanical behavior adjacent to an underground excavation and comparison with physical model test results," Tunnelling and Underground Space Technology, vol. 50, pp. 129-142, 2015.

[18] Q. Gan, S. Cao, and F. Yang, "Effect of deficiencies in the tunnel crown thickness on pressure tunnels with posttensioned concrete linings," Advances in Civil Engineering, vol. 2018, no. 1, Article ID 2757542, 14 pages, 2018.

[19] X. F. Li, H. B. Li, Y. Q. Liu, Q. C. Zhou, and X. Xia, "Numerical simulation of rock fragmentation mechanisms subject to wedge penetration for TBMs," Tunnelling and Underground Space Technology, vol. 53, pp. 96-108, 2016.

[20] W. Peitao, M. Cai, and F. Ren, "Anisotropy and directionality of tensile behaviours of a jointed rock mass subjected to numerical Brazilian tests," Tunnelling and Underground Space Technology, vol. 73, pp. 139-153, 2018.

[21] Y.-S. Jeon, E.-S. Park, S.-K. Chung, D.-H. Lee, and H.-Y. Kim, "Numerical simulation of fracture mechanics and thermomechanical behaviour under low temperature conditions," Tunnelling and Underground Space Technology, vol. 21, no. 34, pp. 470-471, 2006.

[22] D. O. Potyondy and P. A. Cundall, "A bonded-particle model for rock," International Journal of Rock Mechanics and Mining Sciences, vol. 41, no. 8, pp. 1329-1364, 2004.

[23] Y. Z. Lee and W. Schubert, "Determination of the round length for tunnel excavation in weak rock," Tunnelling \& Underground Space Technology Incorporating Trenchless Technology Research, vol. 23, no. 3, pp. 221-231, 2018.

[24] C. Wang and D. D. Tannant, "Rock fracture around a highly stressed tunnel and the impact of a thin tunnel liner for 
ground control," International Journal of Rock Mechanics and Mining Sciences, vol. 41, no. 3, p. 490, 2004.

[25] P. Jane, Research and Application of Macro-And Micro-mechanical Properties of Sandy Pebble Surrounding Rock in Chengdu Area, Chengdu University of Technology, Chengdu, China, 2017.

[26] P. Jane, J. F. Lu, and Y. Z. Zhong, "Study on strength parameters of sandy pebbles under different densities and moisture contents," Science and Technology and Engineering, vol. 16, no. 24, pp. 257-261, 2016.

[27] M. Hu, Physical and Mechanical Properties of Sandy Pebble Soil and Numerical Simulation of Shield Construction Response, South China University of Technology, Guangzhou, China, 2014.

[28] H. T. Liu and X. H. Cheng, "Discrete element analysis of size effect of coarse grained soil," Geotechnical Mechanics, vol. 30, no. 1, 2009. 


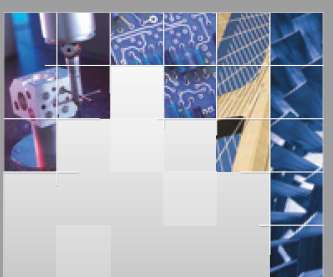

\section{Enfincering}
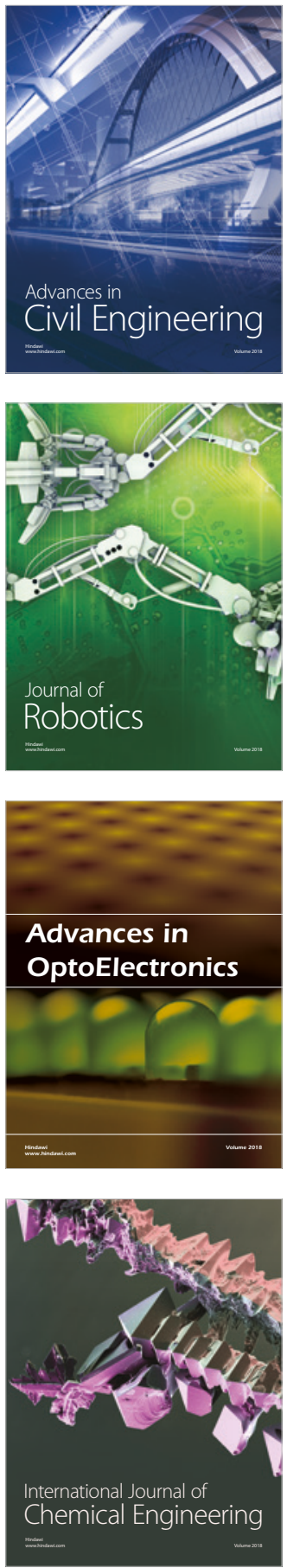

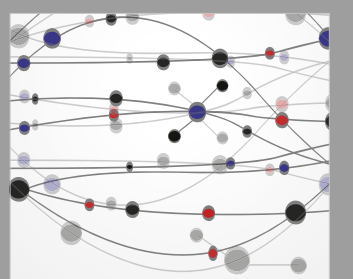

\section{Rotating \\ Machinery}

The Scientific World Journal

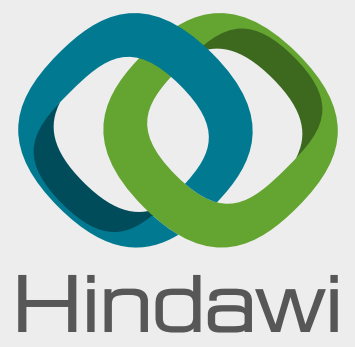

Submit your manuscripts at

www.hindawi.com
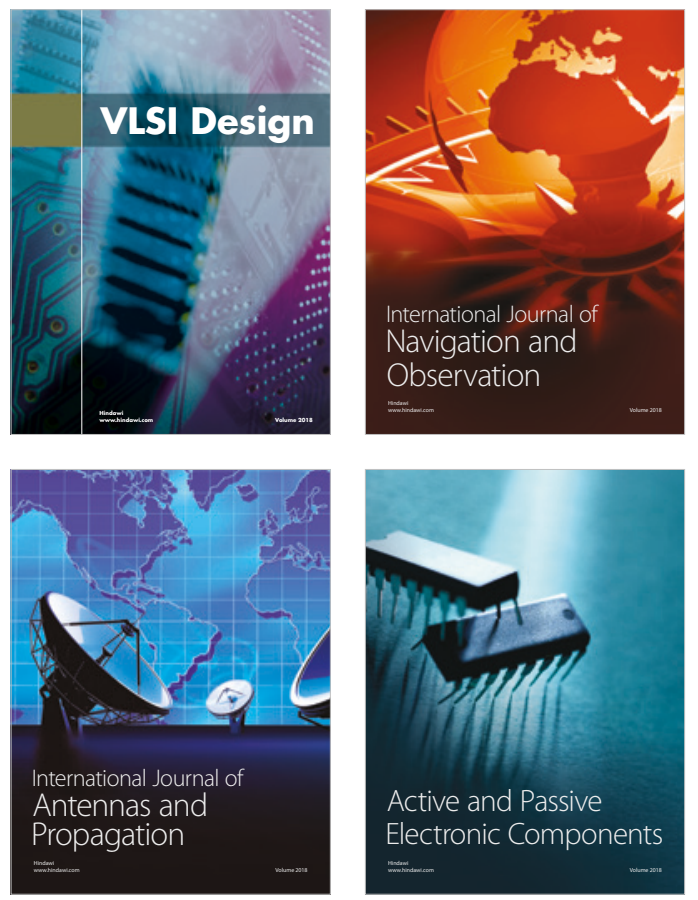
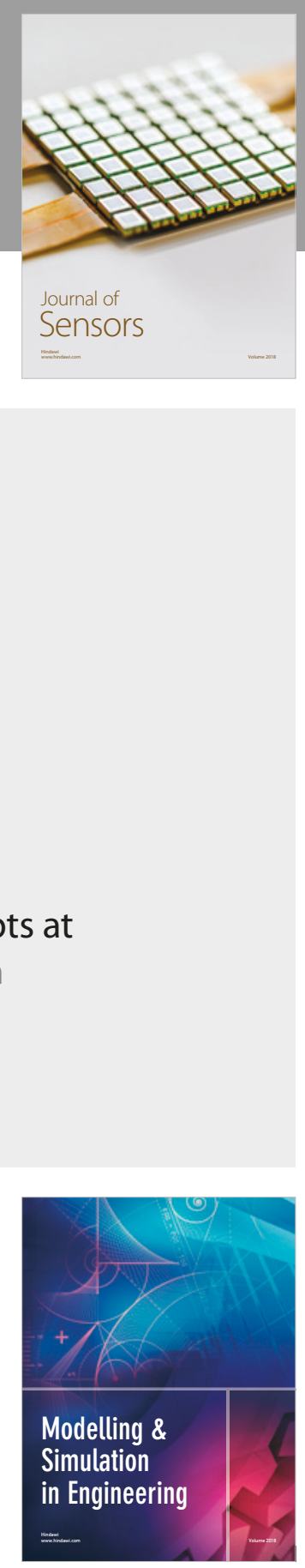

\section{Advances \\ Multimedia}
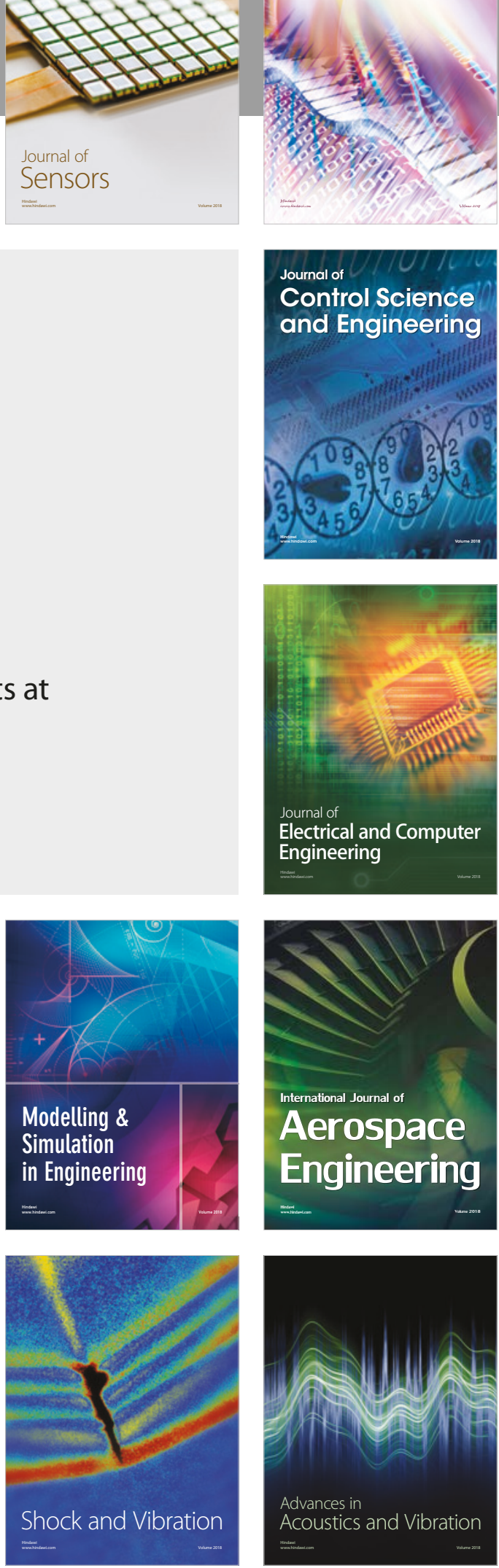